\title{
'Sun Leaper', a Hybrid Tomato, and Its Parent, NC HS-1
}

R.G. Gardner ${ }^{1}$

Department of Horticultural Science, North Carolina State University, Raleigh, NC 27695-7609

Additional index words. Lycopersicon esculentum, vegetable breeding, heat tolerance, disease resistance

'Sun Leaper' is a fresh-market tomato (Lycopersicon esculentum Mill.) hybrid with a desirable combination of plant and fruit characteristics and ability to set fruit under moderately high night temperatures. It resulted from a breeding program to develop an

Received for publication 7 July 1999. Accepted for publication 5 Nov. 1999. The use of trade names in this publication does not imply endorsement by the North Carolina Agricultural Research Service (NCARS) of the products named, nor criticism of similar ones not mentioned. This research was funded by the NCARS and the North Carolina Tomato Growers Association. The cost of publishing this paper was defrayed in part by the payment of page charges. Under postal regulations, this paper therefore must be hereby marked advertisement solely to indicate this fact.

'E-mail address: Randy_Gardner@ncsu.edu improved cultivar for summer production in piedmont and eastern North Carolina, where night temperatures often range from 21 to 25 ${ }^{\circ} \mathrm{C}$. 'Sun Leaper' was tested as NC 92191 and in the Southern Tomato Exchange Program as STEP 744.

\section{Origin}

'Sun Leaper' is the $\mathrm{F}_{1}$ hybrid of NC HS-1 $x$ NC 84173 PVP (Fig. 1). NC 84173 PVP was released in 1990 as a parent line of the hybrid 'Mountain Spring' and was described by Gardner (1992). NC HS-1, an inbred line in the $\mathrm{F}_{9}$ generation, is derived from crosses involving the cultivar TH-318, released by Texas A\&M Univ., as a source of ability to set fruit under high temperature. Segregating generations from crosses leading to NC HS-1 were selected for fruit and plant traits and fruit set under summer conditions in piedmont and eastern North Carolina.

\section{Description}

NC HS-1. Plant habit is determinate ( $s p)$ (Mutschler et al., 1987). The noncurled foliage is medium green and develops a canopy with moderate fruit coverage. The plants grow vigorously and typically outgrow the stake used in the short-stake, string-weave system.

Fruit of NC HS-1 are deep oblate to flattened globular and are symmetrical with a small, smooth, blossom-end scar. Immature fruit are a glossy, uniform green $(u)$ and ripen to an acceptable red exterior and interior color with medium firmness (subjective ratings). Fruit pedicels are jointed and separate easily from the fruit during harvest. NC HS-1 had high total and marketable yields when compared with standard cultivars in trials at Fletcher, N.C. under non-heat stress conditions. Fruit size was smaller than that of 'Sun Leaper' and 'Solar Set' and did not differ from 'Flora-Dade' (Table 1).

NC HS- 1 is resistant $(I, I-2)$ to races 1 and 2 of Fusarium oxysporum f.sp. lycopersici (Sacc.) Snyd. and Hans., the incitant of fusarium wilt, and is resistant $(\mathrm{Ve}$ ) to race 1 of Verticillium dahliae Kleb., the incitant of verticillium wilt. Fruit are highly resistant to radial and concentric cracking and to cuticle cracking (weather check).

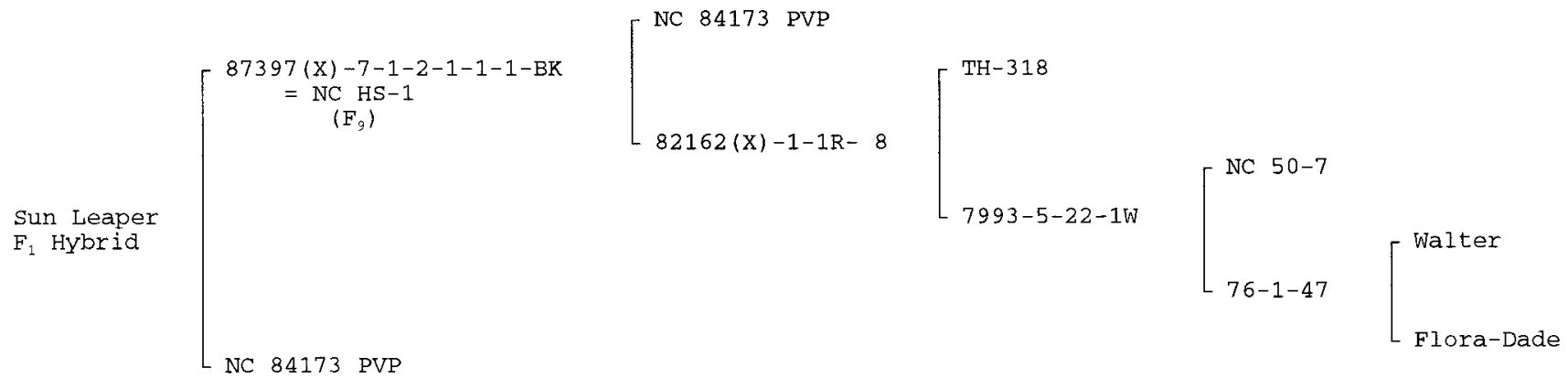

Fig. 1. Pedigrees of 'Sun Leaper' $F_{1}$ hybrid tomato and its parental line, NC HS-1.

Table 1. Comparison of yields and fruit weight of NC HS- 1 and of 'Sun Leaper' with those of standard tomato cultivars in replicated, staked, vine-ripe harvest trials at Fletcher, N.C.

\begin{tabular}{|c|c|c|c|c|}
\hline \multirow[b]{4}{*}{ Cultivar } & \multicolumn{3}{|c|}{ Yield $\left(\mathrm{Mg} \cdot \mathrm{ha}^{-1}\right)$} & \multirow{4}{*}{$\begin{array}{l}\text { Wt/fruit } \\
(\mathrm{g})\end{array}$} \\
\hline & \multirow{3}{*}{$\frac{\text { Early season }^{z}}{\text { Nongraded }}$} & \multicolumn{2}{|c|}{ Total season } & \\
\hline & & & U.S. combination & \\
\hline & & Nongraded & $\operatorname{grade}^{y}$ & \\
\hline NC HS-1 & 32 & 130 & 80 & 212 \\
\hline Flora-Dade & 28 & 110 & 48 & 193 \\
\hline Solar Set & 42 & 105 & 45 & 258 \\
\hline Sun Leaper & 32 & 121 & 76 & 273 \\
\hline $\operatorname{LSD}_{0.05}{ }^{\mathrm{x}}$ & 8 & 15 & 14 & 24 \\
\hline Sun Leaper & 33 & 119 & 81 & 302 \\
\hline Solar Set & 42 & 103 & 48 & 282 \\
\hline Mountain Fresh & 28 & 109 & 77 & 303 \\
\hline Mountain Spring & 35 & 100 & 59 & 340 \\
\hline Mountain Supreme & 24 & 112 & 87 & 227 \\
\hline $\mathrm{LSD}_{0.05}{ }^{\mathrm{w}}$ & 5 & 8 & 8 & 33 \\
\hline
\end{tabular}

${ }^{2}$ First 2 weeks of harvest.

y.S. No. 1 + U.S. No. 2 fruit.

Based on two replicated trials conducted in 1992.

wBased on eight replicated trials averaged over a 4-year period (1994-97). 
'Sun Leaper'. Plant habit is determinate $(s p)$ with medium green, noncurled foliage. The plant is vigorous and provides adequate, but not dense, cover for fruit protection. 'Sun Leaper' has very good adaptability to the shortstake, string-weave system of culture.

Nonripe fruit of 'Sun Leaper' have a uniform, glossy, light green finish $(u)$. Fruit pedicels are jointed. Fruit ripen to a uniform red exterior and interior color and have flavor comparable with that of standard cultivars (subjective ratings by author). Fruit are flattened globular to deep oblate in shape, are symmetrical, and have a small, smooth, blossom-end scar. Fruit are large, comparable with those of 'Solar Set' and 'Mountain Fresh' (Table 1). They are firm at the ripe stage and have a thick wall, resulting in good handling characteristics at the breaker or pink stages of maturity.

Because of lower incidence of rough blossom scar, fruit cracking, and angular fruit shape, 'Sun Leaper' produced U.S. combination grade yields exceeding those of 'Solar
Set' in replicated trials under non-heat stress conditions at Fletcher, N.C. (Table 1). In extensive grower trials in piedmont North Carolina over several years, 'Sun Leaper' consistently produced high yields of large, smooth fruit under high night temperature conditions, whereas quality of 'Solar Set' and 'Heat Wave' were unacceptable because of a high incidence of rough blossom scar. Observations in Florida indicate that the heat-setting ability of 'Sun Leaper' at high temperature may be lower than that of 'Solar Set' and 'Heat Wave'.

'Sun Leaper' is homozygous resistant to fusarium wilt $(I, I-2)$ and to verticillium wilt $(\mathrm{Ve})$. Fruit are resistant to radial and concentric fruit cracking and to cuticle cracking.

Use

'Sun Leaper' is adapted to production of vine-ripe and mature-green fruit. It has performed well in research station and grower plantings throughout the southeastern United States. NC HS-1 is not intended for direct use as a cultivar, but should prove useful in further breeding for improved heat-tolerant cultivars and as a parental line in producing other hybrids with improved fruit set under high temperatures.

\section{Availability}

'Sun Leaper' was released on an exclusive basis for commercial seed production and sales to Novartis Seeds, Inc. Small samples of 'Sun Leaper' and its parental lines for trial and breeding purposes are available from R.G. Gardner, Mountain Horticultural Crops Research and Extension Center, Fletcher, NC 28732-9244.

\section{Literature Cited}

Gardner, R.G. 1992. 'Mountain Spring' tomato; NC 8276 and NC 84173 tomato breeding lines. HortScience 27:1233-1234.

Mutschler, M.A., S.D. Tanksley, and C.M. Rick. 1987 linkage maps of the tomato (Lycopersicon esculentum). Rpt. Tomato Genet. Coop. 37:5-34. 